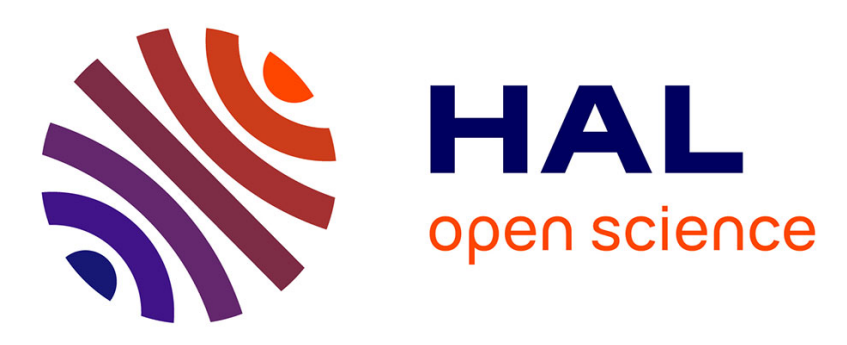

\title{
The neural correlates of tinnitus-related distress
}

Sven Venneste, Mark Plazier, Elsa van Der Loo, Paul van de Heyning, Marco Congedo, Dirk de Ridder

\section{To cite this version:}

Sven Venneste, Mark Plazier, Elsa van Der Loo, Paul van de Heyning, Marco Congedo, et al.. The neural correlates of tinnitus-related distress. NeuroImage, 2010, 52 (2), pp.470-80. 10.1016/j.neuroimage.2010.04.029 . hal-00480500

\section{HAL Id: hal-00480500 https://hal.science/hal-00480500}

Submitted on 4 May 2010

HAL is a multi-disciplinary open access archive for the deposit and dissemination of scientific research documents, whether they are published or not. The documents may come from teaching and research institutions in France or abroad, or from public or private research centers.
L'archive ouverte pluridisciplinaire HAL, est destinée au dépôt et à la diffusion de documents scientifiques de niveau recherche, publiés ou non, émanant des établissements d'enseignement et de recherche français ou étrangers, des laboratoires publics ou privés. 


\section{The neural correlates of tinnitus-related distress}

Sven Vanneste ${ }^{1}$, Mark Plazier ${ }^{1}$, Elsa van der Loo ${ }^{1}$, Paul Van de Heyning ${ }^{2}$, Marco Congedo ${ }^{3}$,

Dirk De Ridder ${ }^{1}$

1. Brai²n, TRI \& Department of Neurosurgery, University Hospital Antwerp, Belgium

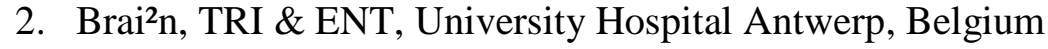

3. Team ViBS (Vision and Brain Signal Processing), GIPSA-lab, National Center for Scientific Research (cnrs), Grenoble Universities, France

Running title: The neural correlates of tinnitus-related distress

Key Words: Tinnitus, distress, LORETA, DLPFC, scACC, precuneus, parahippocampus, amygdala

Acknowledgements: the authors thank Jan Ost, Bram Van Achteren, Bjorn Devree and Pieter van Looy for their help in preparing this manuscript

Correspondence to: Sven Vanneste, Brai ${ }^{2} n$, University Hospital Antwerp, Wilrijkstraat 10, 2650 Edegem, Belgium. Tel: +32 $821 \quad 33$ 36; Fax: +32 3282525 28; email: sven.vanneste@ua.ac.be; website: http://www.brai2n.com. 


\begin{abstract}
Tinnitus is an auditory phantom percept with a tone, hissing, or buzzing sound in the absence of any objective physical sound source. About 6 to $25 \%$ of the affected people report interference with their lives as tinnitus causes a considerable amount of distress. However, the underlying neurophysiological mechanism for the development of tinnitus-related distress remains not well understood. Hence we focus on the cortical and subcortical source differences in resting-state EEG between tinnitus patients with different grades of distress using continuous scalp EEG recordings and Low Resolution Electromagnetic Tomography (LORETA). Results show more synchronized alpha activity in the tinnitus patients with a serious amount of distress with peaks localized to various emotion-related areas. These areas include subcallosal anterior cingulate cortex, the insula, parahippocampal area and amygdala. In addition, less alpha synchronized activity was found in the posterior cingulate cortex, precuneus and DLPFC. A comparison between the tinnitus group with distress and the Nova Tech EEG (NTE) normative database demonstrated increased synchronized alpha and beta activity and less synchronized delta and theta activity in the dorsal anterior cingulate cortex in tinnitus patients with distress. It is interesting that the areas found show some overlap with the emotional component of the pain matrix and the distress related areas in asthmatic dyspnea. Unpleasantness of pain activates the anterior cingulate and prefrontal cortices, amygdala, and insula. As such, it might be that distress is related to alpha and beta activity in the dorsal anterior cingulate cortex, the amount of distress perceived to an alpha network consisting of the amygdala-anterior cingulate cortex-insulaparahippocampal area.
\end{abstract}




\section{Introduction}

Tinnitus is an auditory phantom percept with a tone, hissing, or buzzing sound in the absence of any objective physical sound source (Jastreboff, 1990). In an adult population, up to 10-15\% experience tinnitus continuously (Axelsson and Ringdahl, 1989; Heller, 2003). About 6 to 25\% of the affected people report interference with their lives as tinnitus causes a considerable amount of distress (Baguley, 2002; Eggermont and Roberts, 2004; Heller, 2003), with 2-4 \% suffering in the worst degree (Axelsson and Ringdahl, 1989). The psychological complications such as annoyance, concentration problems, depression, anxiety, irritability, sleep disturbances, and intense worrying can be a result of the constant awareness of this phantom sound (Erlandsson and Holgers, 2001; Scott and Lindberg, 2000). Whereas more people experience a phantom sound, only 1 in 5 of the people who perceive tinnitus is emotionally affected by it. Hence the sound perception and the distress caused by tinnitus might be related to two separate mechanisms/networks in the brain. In the present research we focus on the underlying neurophysiological mechanism for the development of tinnitus-related distress, as this remains not well understood.

Several studies making use of functional magnetic resonance imaging (Kovacs et al., 2006; Melcher et al., 2000; Smits et al., 2007), voxel based morphometry (Landgrebe et al., 2009; Muhlau et al., 2006), PET scan (Lockwood et al., 1999; Mirz et al., 2000a; Mirz et al., 1999), magnetoencephalography (Llinas et al., 1999; Weisz et al., 2007; Weisz et al., 2005; Weisz et al., 2004), electroencephalography (Kadner et al., 2002; Weisz et al., 2004) or repetitive transcranial magnetic stimulation (De Ridder et al., 2006a; De Ridder et al., 2007b, c; Kleinjung et al., 2008) reported that cortical and subcortical changes play a major role in the development and the maintenance of tinnitus. In analogy to neuropathic pain, tinnitus is related to reorganization (Flor 
et al., 1995; Muhlnickel et al., 1998) and hyperactivity (Eggermont and Roberts, 2004; Kaltenbach and Afman, 2000; Salvi et al., 2000) of the auditory central nervous system with coactivation of non-auditory areas such as the insula (Smits et al., 2007), anterior cingulate cortex (Muhlau et al., 2006; Plewnia et al., 2007a), posterior cingulate cortex (Plewnia et al., 2007a; Plewnia et al., 2007b), dorsal lateral prefrontal cortex (Kleinjung et al., 2008),

It has been stated that there are clinical, pathophysiological and treatment analogies between phantom pain and phantom sound (De Ridder et al., 2007a; Moller, 1997, 2000; Tonndorf, 1987). The anterior cingulate cortex (Mobascher et al., 2009) and the insula (Brooks et al., 2005), which interact with the prefrontal cortex and amygdala play a central role in emotioncognitive aspects of pain processing (Craig, 2003; Peyron et al., 2000). During distress in the setting of posttraumatic stress disorder, activation of the amygdala, insula, medial prefrontal cortex, and anterior cingulate cortex has been revealed (Vermetten et al., 2007). The principal components of a general emotional network (Critchley, 2005; Phan et al., 2002) involving the amygdala, anterior cingulate cortex, insula and prefrontal cortex may be the same as the emotional component involved in tinnitus.

In the present study, we focus on the cortical and subcortical source differences in restingstate eyes-closed EEG between tinnitus patients with different grades of distress. Using continuous scalp EEG recordings and Low Resolution Electromagnetic Tomography (LORETA), a tomographic inverse solution imaging technique (Pascual-Marqui et al., 1994), we set out both the spectral characteristics and topography of differential activations in tinnitusrelated distress.

\section{Methods}




\section{Participants}

Twenty-seven patients $(\mathrm{N}=27 ; 11$ males and 16 females $)$ with chronic tinnitus participated in this study, with a mean age of $53.85(S D=11.43)$. Tinnitus was considered chronic if its onset dated back 1 year or more. Individuals with pulsatile tinnitus, Ménière disease, otosclerosis, chronic headache, neurological disorders such as brain tumors, and individuals being treated for mental disorders were excluded from the study in order to obtain a more homogeneous sample. All patients were investigated for the extent of hearing loss using audiograms. Tinnitus patients were tested for the frequency and the minimum masking level of their tinnitus. They were interviewed as to their perceived location of the tinnitus (exclusively in the left ear, predominantly in the left ear, in both ears, and centralized in the middle of the head (bilateral), predominantly in the right ear, exclusively in the right ear). Table 1 shows the male-female ratio, age, tinnitus duration, tinnitus type and tinnitus laterality. There were no significant differences in age and tinnitus duration between patients of the different groups (both $p>.15$ ).

Patients were also given the validated Dutch version of the Tinnitus Questionnaire (Meeus et al., 2007) originally published by Goebel and Hiller (Goebel and Hiller, 1994). Goebel and Hiller described this TQ as a global index of distress and the Dutch version was further confirmed as a reliable measure for tinnitus-related distress (Meeus et al., 2007; Vanneste et al., 2009). Based on the total score on the TQ, participants were assigned to a distress category: slight (0-30 points;

grade 1), moderate (31-46; grade 2), severe (47-59; grade 3), and very severe (60-84; grade 4) distress. Furthermore, Goebel and Hiller (1994) stated that grade 4 tinnitus patients are psychologically decompensated, indicating that patients categorized into this group cannot cope with their tinnitus. In contrast, patients that have a score lower than 60 on the TQ can cope with their tinnitus. Based on the categorization we compared subjects (1) with low versus with high 
distress (grade 1 and 2 versus grade 3 and 4); (2) highly distressed tinnitus patients who can cope versus who cannot cope with tinnitus (grade 3 versus 4); (3) coping patients with low versus high distress (grade 1 versus grade 3 ).

\section{EEG data collection}

EEG recordings were obtained in a fully lighted room with each participant sitting upright on a small but comfortable chair. The actual recording lasted approximately $5 \mathrm{~min}$. The EEG was sampled with 19 electrodes (Fp1, Fp2, F7, F3, Fz, F4, F8, T7, C3, Cz, C4, T8, P7, P3, Pz, P4, P8, $\mathrm{O} 1 \mathrm{O} 2)$ in the standard 10-20 International placement referenced to linked ears and impedances were checked to remain below $5 \mathrm{k} \Omega$. Data were collected eyes-closed (sampling rate $=1024 \mathrm{~Hz}$, band passed $0.15-200 \mathrm{~Hz}$ ). Data were resampled to $128 \mathrm{~Hz}$, band-pass filtered (fast Fourier transform filter) to 2-44 Hz and subsequently transposed into Eureka! Software (Congedo, 2002), plotted and carefully inspected for manual artifact-rejection. All episodic artifacts including eye blinks, eye movements, teeth clenching, body movement, or ECG artifact were removed from the stream of the EEG. Average Fourier cross-spectral matrices were computed for bands delta (2-3.5 Hz), theta $(4-7.5 \mathrm{~Hz})$, alpha1 $(8-10 \mathrm{~Hz})$, alpha2 $(10.5-12.5 \mathrm{~Hz})$, beta1 (13-16.5 Hz), beta2 (17-20.5 Hz), beta3 $(21-24.5 \mathrm{~Hz})$, beta4 $(25-28.5 \mathrm{~Hz})$, beta5 $(29-32.5 \mathrm{~Hz})$, and gamma (33-44 $\mathrm{Hz})$.

\section{NTE normative database}

Also the normative database of the Nova Tech EEG (NTE), Inc, Mesa, AZ (N = 21) was used (http://www.novatecheeg.com/). None of these subjects was known to suffer from tinnitus. 
Exclusion criteria for the NTE database were known psychiatric or neurological illness, psychiatric history of drug/alcohol abuse in a participant or any relative, current psychotropic/CNS active medications, history of head injury (with loss of consciousness) or seizures, headache, physical disability. To build the database about 3-5 min of EEG was continuously recorded while participant sat with the eyes closed on a comfortable chair in a quiet and dimly lit room. EEG data were acquired at the 19 standard leads prescribed by the 10-20 international system (FP1, FP2, F7, F3, FZ, F4, F8, T3, C3, CZ, C4, T4, T5, P3, PZ, P4, T6, O1, O2) using both earlobes as reference and enabling a $60 \mathrm{~Hz}$ notch filter to suppress power line contamination. The resistance of all electrodes was kept below $5 \mathrm{k} \Omega$. Data of the NTE database were acquired using the 12-bit A/D NeuroSearch-24 acquisition system (Lexicor Medical Technology, Inc. Boulder, CO) and sampled at 128. In the database all biological, instrumental and environmental artifacts had been removed.

\section{LORETA imaging}

LORETA is a brain imaging method that computes inverse solutions that approximate the cortical sources using a three-shell spherical model registered to the Talairach human brain atlas (Talairach and Tournoux, 1988) from EEG recordings (http://www.uzh.ch/keyinst/NewLORETA/LORETA01.htm) (Pascual-Marqui et al., 1994). The LORETA solution space is restricted to the cortical grey matter in the digitized Talairach atlas with a total of 2394 voxels at $7 \mathrm{~mm}$ spatial resolution (Talairach and Tournoux, 1988; (PascualMarqui et al., 1999). The LORETA inverse solution corresponds to the 3D distribution of electrical neuronal activity that features a maximum similarity (i.e. maximum synchronization) in terms of orientation and strength between neighboring neuronal populations in adjacent 
voxels. The imaging is therefore particularly tuned towards synchronized brain activities as they occur, e.g., in spreading oscillatory activations. Since LORETA takes explicitly into account that scalp electric potentials are determined up to an arbitrary additive constant, the final LORETA solution is independent of the electrical reference used. The Laplacian penalty term in sLORETA tunes the solution towards the activation of concurrent neuronal populations and limits the detection of very circumscribed and small generators. The gain of this strategy consists of its particular capacity to localize generators with a low localization error of 1-2 voxels of $7 \mathrm{~mm}$. (Mulert et al., 2004; Pascual-Marqui et al., 2002).

\section{LORETA analysis}

For every frequency band and subject, the current density modules at each voxel (current density amplitude) were smoothed with a $21 \mathrm{~mm}$ 3-dimensional moving average filter, normalized, and finally log-transformed. Log transformation of power estimates is routinely performed in EEG and LORETA to approximate data Gaussianity (John et al., 1987). With LORETA, some smoothing is advisable to counteract anatomical and localization errors due to inter-individual differences in head geometry and electrodes placement. Spatial normalization consists of normalizing the square root of the sum of squared current density values for each subject at all voxels to equal unity. This manipulation eliminates confounding variables such as the inter-individual variability in skull thickness and electrode impedance, without constraining the analysis on relative power measures, which is the solution usually adopted in EEG studies. Current density amplitude estimates computed and pre-processed as described provided the data for statistical analysis. 
To compare voxel-by-voxel the current density amplitudes of the tinnitus distress, we used the permutation multiple comparison $t$-sum approach, which accounts for multiple comparison (Congedo et al., 2004). Instead of relying on the max statistic to build the empirical null distribution, we rely on the sum statistic. The sum statistic has been known since a long time as an appropriate statistic to test the omnibus hypothesis, i.e., the hypothesis of no effect at no location (Arndt et al., 1996; Karniski et al., 1994). As compared to the max statistic, it is more sensitive to large flat regions of activation. The t-sum is a step-down procedure. It sorts the hypotheses in increasing order of absolute t-values and test sequentially the omnibus hypothesis for significance, starting with all voxels and excluding progressively the most significant one-byone down until only the least significant voxel is left. At each step, the sum of the observed absolute magnitude is compared to the empirical distribution of such a sum obtained by data permutations. If the omnibus hypothesis is rejected at least one univariate hypothesis is false, thus the procedure rejects the hypothesis with highest absolute t-value and proceeds down with the remaining hypotheses until the omnibus test is no more rejected or all have been rejected. Data-permutation approaches adaptively accounts for the correlation structure of the variables, an embedded feature of all electrophysiological measurements (Holmes et al. 1996). Testing multiple hypotheses relating to correlated variables should influence correction for multiple comparisons. For instance, if two variables are independent, Bonferroni correction is the appropriate way to correct. If correlation is present a less stringent criterion is requested. At the limit, when two variables are perfectly correlated, we are actually testing two times the same variable. In this case no correction for multiple hypotheses at all is necessary. The good thing about permutation tests is that they naturally account for the correlation structure of the variables, as the data at hand is used to perform the test and such structure remains after shuffling 
the data. In EEG the correlation among variables (e.g., electrodes, voxels, etc) is very high, so permutation tests suit well EEG data.

We performed one voxel-by-voxel test (comprising 2394 voxels each) for each of the 9 frequency band pass regions (delta, theta, alpha1, alpha2, beta1, beta2, beta3, beta4, beta5, and gamma).

\section{Region of interest analysis}

The log-transformed electric current density was averaged across all voxels belonging to the region of interest, respectively BA7 left, BA7 right, BA 9-46 right, BA13 left, BA13 right, BA23 left, BA 23 right, BA25 left and right, BA36-37 left, and BA36-37 right separately for frequency band alpha1 $(8-10 \mathrm{~Hz})$ and alpha2 $(10.5-12 \mathrm{~Hz})$. A multiple linear regression was used between the total score on TQ as a global index of distress and changes in ROI using backward approach (i.e. initially using all ROI and eliminating those regions that do not show statistical significance in a step-wise manner).

\section{Results}

High versus Low distress

The majority of the frequency band parameters were similar in low and high distress tinnitus patients: delta $(2-3.5 \mathrm{~Hz})$, theta $(4-7.5 \mathrm{~Hz})$, beta1 $(13-16.5 \mathrm{~Hz})$, beta2 $(17-20.5 \mathrm{~Hz})$, beta3 (21$24.5 \mathrm{~Hz})$, beta4 $(25-28.5 \mathrm{~Hz})$, beta5 $(29-32.5 \mathrm{~Hz})$, and gamma $(33-44 \mathrm{~Hz})$. Figure 1 illustrates that the LORETA current source density in the alpha1 $(8-10 \mathrm{~Hz})$ band was higher for high 
distress tinnitus patients than among low distress tinnitus patients in posterior subcallosal anterior cingulate (BA25) extending into the nucleus accumbens-VTA area, parahippocampal gyrus (BA36) and amygdala. Figure 2 illustrates that alpha2 (10.5-12.5 Hz) was also higher in the parahippocampal gyrus (BA36 and 37), amygdala and in extension the middle temporal gyrus (BA21) for the high distress tinnitus patients and higher in the posterior cingulate (BA23), precuneus (BA7) for the low distress tinnitus patients. The maximum $t$-statistic across the entire volume was 4.41 and 4.30 for alpha1 and alpha2 respectively.

\section{Non-coping versus Coping in high distress}

Again, the majority of the frequency band parameters were similar in coping (grade 3) and non-coping highly distressed tinnitus (grade 4) patients: delta $(2-3.5 \mathrm{~Hz})$, theta $(4-7.5 \mathrm{~Hz})$, beta1 (13-16.5 Hz), beta2 (17-20.5 Hz), beta3 $(21-24.5 \mathrm{~Hz})$, beta4 $(25-28.5 \mathrm{~Hz})$, beta5 $(29-32.5 \mathrm{~Hz})$, and gamma (33-44 Hz). LORETA current source density in the alpha1 $(8-10 \mathrm{~Hz})$ band was higher for non-coping (grade 4) tinnitus patients than among tinnitus patients who can cope (grade 3) with their tinnitus in insula (BA 13), anterior cingulate (BA25), parahippocampal gyrus (BA37) and amygdala and the opposite for precuneus (BA7)(see figure 3). For alpha2 (10.5-12.5 $\mathrm{Hz}$ ) it was also higher in the insula (BA13) subcallosal gyrus (BA25), parahippocampal gyrus (BA36) and amygdala for non-coping individuals and higher in the posterior cingulate (BA23), precuneus (BA7) for the non-coping individuals (see figure 4). The maximum $t$-statistic across the entire volume was -4.81 and -3.60 for alpha1 and alpha2 respectively. 
Similar to the results above, no differences could be found for most frequency bands when comparing tinnitus-patient who can cope with low (grade 1) versus high distress (grade 3) in delta $(2-3.5 \mathrm{~Hz})$, theta $(4-7.5 \mathrm{~Hz})$, beta1 $(13-16.5 \mathrm{~Hz})$, beta2 $(17-20.5 \mathrm{~Hz})$, beta3 $(21-24.5 \mathrm{~Hz})$, beta4 $(25-28.5 \mathrm{~Hz})$, beta5 $(29-32.5 \mathrm{~Hz})$, and gamma $(33-44 \mathrm{~Hz})$ bands. Yet LORETA current source density in the alpha1 $(8-10 \mathrm{~Hz})$ band was higher for low distress coping tinnitus patients compared to high distress coping tinnitus patients in dorsal lateral prefrontal cortex (BA9 and BA46) and precentral gyrus (BA6). Furthermore figure 6 illustrates that alpha2 (10.5-12.5 Hz) was higher in high distress coping tinnitus patients than among low distress coping tinnitus patients in the precuneus (BA7) and the opposite for dorsal lateral prefrontal cortex (BA9 and BA46) and ventrolateral prefrontal cortex (BA8). The maximum $t$-statistic across the entire volume was 3.42 and 3.50 for alpha1 and alpha2 respectively.

\section{Frequency analysis of alpha rhythms}

To determine whether the differences found might be the results due to discrepancies of the individual alpha frequency (IAF) peaks between individuals within the distinct groups (i.e. grade 1, 2, 3 and 4) we identified the IAF peak according to literature guidelines (Klimesch, 1996; Klimesch et al., 1998; Klimesch et al., 1999). This individual alpha frequency peak was defined as the frequency within the range of $6-13 \mathrm{~Hz}$ range of the EEG spectrum showing maximum power. The mean individual alpha frequency was 10.62, 10.08, 9.95 and $10.21 \mathrm{~Hz}$ for respectively grade 1, 2, 3 and 4 tinnitus patients. There was no significant inter-groups difference in the IAF peak as evaluated by an $\operatorname{ANOVA}(p>.18)$. 
A stepwise backward regression analysis was performed with the dependent variable as TQ and the ROI as the independent variables separately for the frequency bands alpha1 $(8-10 \mathrm{~Hz})$ and alpha2 (10.5-12.5 Hz). The regression was run to assess the relative contribution of specific brain areas to the tinnitus-related distress.

For alpha 1 , backward regression revealed a fit of $\mathrm{R}^{2}=.31$. The Analysis of Variance (ANOVA) revealed that the overall model was significant $(F(2,25)=4.77, p<.05)$, where only BA9-46 and BA25 contributed significantly. The regression equation is therefore, $\mathrm{TQ}=26.90-$ 17.98 BA9-46 + 19.83 BA25 (see table 2).

For alpha 2, a relatively large proportion of the variance was explained by the backward regression model demonstrated $\left(\mathrm{R}^{2}=.65\right)$. The Analysis of Variance (ANOVA) revealed that the overall model was significant $(F(2,25)=5.15 p<.01)$ where BA25, BA9-46, BA36-37 left as well as right, and BA23 left as well right contributed significantly. The regression equation is therefore, TQ $=33.95-19.92$ BA9-46 + 116.71 BA23 left -120.56 BA23 right + 25.86 BA25 19.57 BA36-37 left + 22.00 BA36-37 right (see table 2).

\section{Tinnitus distress group versus NTE normative database}

To explore the data further, a comparison was made between the tinnitus group with distress (grade 2, 3 and 4) and the NTE normative database. Figure 7 illustrates that the LORETA current source density in the alpha (8-12 Hz; alpha1 $8-10 \mathrm{~Hz} \&$ alpha2 $10.5-12.5 \mathrm{~Hz})$ and beta3 (21-24.5 $\mathrm{Hz}$ ) band was higher for tinnitus patients with distress in anterior cingulate cortex (BA24 and BA32). The opposite, namely decreased delta (2-3.5 Hz) and theta (4-7.5 Hz) activity was found for tinnitus patients with distress in comparison to NTE normative database in anterior cingulate 
cortex (BA24 and 32). Also for beta4 $(25-28.5 \mathrm{~Hz})$ and beta5 $(29-32.5 \mathrm{~Hz})$ a significant increase was found in anterior cingulate cortex (BA24 and BA32) for tinnitus patients with distress in comparison to the NTE normative database.

Hearing loss

No significant differences were found for hearing loss between the different grades $(p>.43)$, as measured by the loss in decibels (dB SPL) at the tinnitus frequency.

\section{Discussion}

In this study significantly more synchronized activity in highly distressed tinnitus patients was found in various emotion-related areas (see table 3 for overview). These areas include subcallosal anterior cingulate cortex (scACC), anterior insula cortex (AIC), parahippocampal area and amygdala. In addition, less synchronized activity was found in the posterior cingulate cortex (PCC), precuneus, dorsal lateral prefrontal cortex (DLPFC), and ventrolateral prefrontal cortex (VLPFC) for patients with high levels of distress. A stepwise backward regression analysis was performed which revealed that the scACC, parahippocampal area, PCC, and DLPFC contributed significantly to emotion-related tinnitus. For the comparison of tinnitusrelated distress patients we only found differences within the alpha1 $(8-10 \mathrm{~Hz})$ and alpha2 (10.5$12.5 \mathrm{~Hz}$ ) frequency band. Yet, for the comparison of distressed tinnitus patients in comparison to the NTE normative database also decreased delta, theta activity and increased alpha and beta activity was found in the dorsal anterior cingulate cortex (dACC). 
Since our recordings were performed in the absence of any stimulus presentation, we assume that these areas demonstrate continuously increased and decreased synchronized activity in tinnitus patients depending on the amount of distress.

\section{Non-auditory Brain areas involved in tinnitus}

Our findings are in line with recent studies, using various methodologies, suggesting that nonauditory brain structures are also involved in tinnitus. Using voxel-based morphometry it was shown that structural differences exist between tinnitus sufferers and controls in gray matter, both within the auditory system such as posterior thalamus and in non-auditory structures such as the subcallosal cingulate region including the nucleus accumbens and the scACC (Muhlau et al., 2006). In a PET study increased neural activity for tinnitus sufferers was demonstrated in the right hemisphere, on the middle frontal and middle temporal regions as well as in lateral mesial posterior sites (Mirz et al., 1999). In a MEG study more reduction in alpha (8-12 Hz), increase in delta $(1.5-4 \mathrm{~Hz})$ was found in temporal regions, left frontal and right parietal areas (Weisz et al., 2005) as well as increased functional connectivity in the right frontal lobe and anterior cingulum (Schlee et al., 2008). In accordance with these previous claims, our results confirm that nonauditory areas are also active for tinnitus-related distress.

\section{Brain areas for tinnitus-related distress}

In general, our findings reveal significant activation in different brain areas that are related to attentional and emotional processing, namely scACC, dACC, VLPFC, DLPFC, parahippocampal area, AIC, PCC and precuneus. 
Results showed more alpha activity in scACC for highly distressed tinnitus patients. Patients with high distress who cannot cope with their tinnitus present with more alpha activity in the scACC in comparison to highly distressed individuals who can cope with their tinnitus. Increased activity in posterior scACC extending into nucleus accumbens-ventral tegmental area is involved in processing of aversive sounds (Zald and Pardo, 2002) and unpleasant music (Blood et al., 1999) as well as tinnitus (Muhlau et al., 2006). It has also been implicated as the key component of social distress (Masten et al., 2009), suggesting activity in this area might not be specific for tinnitus. This area in animals has been considered a visceromotor cortex, due to its connections with the parasympathetic nucleus tractus solitarius (Frysztak and Neafsey, 1994) and the sympathetic areas in the periaquaductal grey (Ongur and Price, 2000). Furthermore it is functionally connected to the amygdala, insula, parahippocampal area, orbitofrontal cortex and VLPFC and anticorrelated to the dorsal ACC and precuneus (Kahn et al., 2008; Margulies et al., 2007; Stein et al., 2007)

In comparison to the NTE normative database tinnitus patients with distress have increased alpha and beta activity and decreased delta, theta activity in dACC. Interestingly, whenever new information is presented, activity levels of the dACC reflect the salience of the new information for predicting future outcomes (Behrens et al., 2007; Critchley, 2005), guiding optimal decision making in an uncertain world (Kennerley et al., 2006). The human dACC has developed a parallel specialization for motivational drive via a thalamocortical pathway relaying in the mediodorsal thalamus (Craig, 2002). Thus the dorsal anterior cingulate might be involved in persisting attention to the tinnitus.

In addition, less alpha activation in the VLPFC and DLPFC was found for highly distressed individuals coping with their tinnitus. In previous research activity in DLPFC and VLPFC has been associated with cognitive control (Gray et al., 2005). The DLPFC is part of the 
frontoparietal control system (Vincent et al., 2008) which is interposed between an exteroception-related dorsal attention system and an interoception-related hippocampal memory system. Tinnitus can be considered an interoceptive sound perception, and the DLPFC has been implicated in tinnitus (Mirz et al., 2000a) and aversive sound perception (Mirz et al., 2000b). As such, it can be hypothesized that decreased activity in DLPFC might prevent patients with high distress to have control over their tinnitus. The DLPFC has a bilateral facilitator effect on auditory memory storage (Alain et al., 1998) and contains auditory memory cells (Bodner et al., 1996). The DLPFC also exerts early inhibitory modulation of input to primary auditory cortex in humans (Knight et al., 1989) and has been found to be associated with auditory attention (Alain et al., 1998; Lewis et al., 2000; Voisin et al., 2006) resulting in top-down modulation of auditory processing (Mitchell et al., 2005). This was further confirmed by electrophysiological data indicating that tinnitus might occur as the result of a dysfunction in the top-down inhibitory processes (Norena et al., 1999). Interestingly, a recent study reported that coupling between ACC and the right frontal lobe correlates negatively with tinnitus intrusiveness, which is defined by the authors as how bothersome and obtrusive the tinnitus is perceived (Schlee et al., 2008). This latter finding is in accordance with our results which revealed increased alpha and beta activity in the dACC and decreased activity in the DLPFC. Additionally, Jastreboff described the PFC as a "candidate for the integration of sensory and emotional aspects of tinnitus" (Jastreboff 1990). This is in accordance with the proposal that a general function of the DLPFC is to integrate emotion and cognition (Gray et al., 2002).

More alpha activity in both the left and right AIC was also found for patients with severe tinnitus-related distress who can or cannot cope with these phantom sounds. Imaging studies on the insula associated increased activity within this area with subjective emotional and bodily awareness (Craig, 2003), as well as interoception (Craig, 2003). The AIC has been implicated in 
autonomic nervous system control (Critchley, 2005; Critchley et al., 2004; Oppenheimer, 1993; Oppenheimer et al., 1992) and might therefore be related to the autonomic components involved in distress (Critchley et al., 2000; Wang et al., 2005), induced by the phantom sound. In a recent study it was further revealed that the insula is involved in pain sensitivity (Baliki et al., 2009). The combined activity of the AACC and AIC predicts how intense a pain stimulus is perceived (Boly et al., 2007). This also suggests that the dACC-AIC activity is not specific for tinnitus but is related to a more general function, possibly the autonomic component of a sensory stimulus.

The involvement of the parahippocampal area might be related to the constant updating of the tinnitus percept, and as such preventing habituation (De Ridder et al., 2006b). Cells in the human hippocampus and parahippocampal areas respond to novel stimuli with an increase in firing. However, already on the second presentation of a stimulus, neurons in these regions show very different firing patterns. In the parahippocampal region there is dramatic decrease in the number of cells responding to the stimuli (Viskontas et al., 2006), suggesting a rapid habituation. This rate of response decrement during trains of several stimulus repetitions is linear for acoustic responses (Wilson et al., 1984). In contrast to the rapid auditory habituation in the parahippocampal area, in the hippocampus there is recruitment of a large subset of neurons showing inhibitory responses (Viskontas et al., 2006). Thus a novel stimulus normally is associated with parahippocampal habituation and active hippocampal inhibitory activity. Repetitive auditory stimuli both in animals (Bickford et al., 1993) and humans (Boutros et al., 2008) lead to attenuation of ERPs, but with differences in hippocampal and parahippocampal areas, as early hippocampal ERPs are not attenuated, in accordance with the abovementioned single cell recordings. Based on these data it can be hypothesized that in tinnitus this mechanism is disrupted with persistent parahippocampal activity, preventing habituation. The parahippocampal area has been hypothesized to play a central role in memory recollection, 
sending information from the hippocampus to the association areas and a dysfunction in this mechanism is posited as an explanation for complex auditory phantom percepts such as auditory hallucinations (Diederen et al.). In line with this hypothetical mechanism tinnitus can be seen as a result of constant sending of stored auditory information from the hippocampus to the auditory association areas by persistent parahippocampal activity.

This is compatible with electrophysiological studies demonstrating that auditory habituation is disrupted after amygdalohippocampal resections in humans (Hamalainen et al., 2007). Furthermore injecting amibarbital, a short-acting barbiturate, supraselectively in the anterior choroidal artery, which supplies the amygdalahippocampal area, contralaterally to the side on which the tinnitus is perceived, can temporarily suppress the tinnitus in some patients (De Ridder et al., 2006b) confirming these electrophysiological data. It has therefore been proposed that a fundamental function in tinnitus of the amygdalahippocampal structures is the establishment of auditory memory for tinnitus (Shulman, 1995).

The PCC has been shown to be involved in cognitive evaluation and memorization of sensory input (Vogt et al., 1992). A decrease in this cognitive evaluation could therefore lead to an increased emotional distress by insufficient cognitive appraisal of the unimportance of the tinnitus percept. Functional connectivity has shown that the dorsal ACC is anticorrelated to the PCC and precuneus (Margulies et al., 2007), compatible with the anticorrelated alpha activity in this study.

The exact role of the precuneus in tinnitus is not established yet. In general this area is a highly integrative structure, supposed to be involved in visuospatial imagery, episodic memory, self-consciousness and the shifting of attention (Le, 1998). The precuneus is also involved in unpleasant music perception (Blood et al., 1999), auditory imagery (Yoo et al., 2001), and auditory memory retrieval (Buckner et al., 1996). Opposite to Mirz et al. (1999) who found 
increased activation in the precuneus using PET, we found decreased synchronized activity in this area.

Delta, Theta, Alpha and Beta activity

Severe distress such as in posttraumatic stress disorder is associated with increased beta activity especially over frontal and central areas (C3,C4,F3,F4) (Begic et al., 2001; Jokic-Begic and Begic, 2003). In control subjects the dorsal part of the anterior cingulate and the prefrontal cortex generates frontal midline theta (alternating with the VMPFC) (Asada et al., 1999). In distressed tinnitus patients in contrast to controls low frequency activity (delta and theta) in the dorsal ACC is decreased, i.e. normal theta activity is decreased, and alpha1, alpha2 and beta3 activity is increased. In highly distressed vs. lowly distressed patients alpha1 and alpa2 is even more increased, suggesting that the amount of alpha activity correlates with the amount of distress. The beta3 activity does not differ between the high and low distress groups, indicating that it is equally elevated in both groups. Beta activity might therefore represent a more general distress activity, compatible with what is known for PTSD.

\section{Tinnitus intensity and tinnitus distress}

On the one hand it has been shown that tinnitus intensity correlates with the current density of gamma band activity in the contralateral auditory cortex (van der Loo et al., 2009). On the other hand our findings suggest that the amount of distress in tinnitus patients is related to an alpha network consisting of the amygdala-ACC- insula-parahippocampal area. 
This distress network might not be a unique to tinnitus but it shares components such as the amygdala-ACC and insula which are also involved in the affective aspects of pain (Moisset and Bouhassira, 2007; Price, 2000). As it has been shown that some of these brain structures are also shared between pain and dyspnea in asthma (von Leupoldt et al., 2009) it can be proposed that this network represents an aspecific general distress network which can become activated by different triggers.

\section{In conclusion}

Several prior studies on the neurophysiology of tinnitus focused primarily on changes in the auditory system. Nevertheless, several imaging studies showed activation of higher-order association areas and the limbic system during tinnitus perception (Gardner et al., 2002; Giraud et al., 1999; Plewnia et al., 2007b). The attentional and emotional state is tightly connected with tinnitus perception and the related distress (Folmer et al., 2001; Newman et al., 1997). It is interesting that the areas found are similar to the emotional components of the pain matrix (Craig, 2003; Critchley, 2005; Phan et al., 2002; Peyron et al., 2000). Unpleasantness of pain activates the anterior cingulate and prefrontal cortices (Mobascher et al., 2009), amygdala, and insula (Brooks et al., 2005). This suggests that the perception of tinnitus and pain intensity could be related to auditory and somatosensory cortex activation respectively, but that the distress associated with its perception might be related to activation of a common 'emotional and attentional distress network'. 


\section{Reference}

Alain, C., Woods, D.L., Knight, R.T., 1998. A distributed cortical network for auditory sensory memory in humans. Brain Res 812, 23-37.

Arndt, S., Cizadlo, T., Andreasen, N.C., Heckel, D., Gold, S., O'Leary, D.S., 1996. Tests for comparing images based on randomization and permutation methods. J Cereb Blood Flow Metab 16, 1271-1279.

Asada, H., Fukuda, Y., Tsunoda, S., Yamaguchi, M., Tonoike, M., 1999. Frontal midline theta rhythms reflect alternative activation of prefrontal cortex and anterior cingulate cortex in humans. Neurosci Lett 274, 29-32.

Axelsson, A., Ringdahl, A., 1989. Tinnitus--a study of its prevalence and characteristics. Br J Audiol 23, 53-62.

Baguley, D.M., 2002. Mechanisms of tinnitus. Br Med Bull 63, 195-212.

Baliki, M.N., Geha, P.Y., Apkarian, A.V., 2009. Parsing pain perception between nociceptive representation and magnitude estimation. J Neurophysiol 101, 875-887.

Begic, D., Hotujac, L., Jokic-Begic, N., 2001. Electroencephalographic comparison of veterans with combat-related post-traumatic stress disorder and healthy subjects. Int J Psychophysiol 40, 167-172.

Behrens, T.E., Woolrich, M.W., Walton, M.E., Rushworth, M.F., 2007. Learning the value of information in an uncertain world. Nat Neurosci 10, 1214-1221.

Bickford, P.C., Luntz-Leybman, V., Freedman, R., 1993. Auditory sensory gating in the rat hippocampus: modulation by brainstem activity. Brain Res 607, 33-38.

Blood, A.J., Zatorre, R.J., Bermudez, P., Evans, A.C., 1999. Emotional responses to pleasant and unpleasant music correlate with activity in paralimbic brain regions. Nat Neurosci 2, 382-387. 
Bodner, M., Kroger, J., Fuster, J.M., 1996. Auditory memory cells in dorsolateral prefrontal cortex. Neuroreport 7, 1905-1908.

Boly, M., Balteau, E., Schnakers, C., Degueldre, C., Moonen, G., Luxen, A., Phillips, C., Peigneux, P., Maquet, P., Laureys, S., 2007. Baseline brain activity fluctuations predict somatosensory perception in humans. Proc Natl Acad Sci U S A 104, 12187-12192.

Brooks, J.C., Zambreanu, L., Godinez, A., Craig, A.D., Tracey, I., 2005. Somatotopic organisation of the human insula to painful heat studied with high resolution functional imaging. Neuroimage 27, 201-209.

Buckner, R.L., Raichle, M.E., Miezin, F.M., Petersen, S.E., 1996. Functional anatomic studies of memory retrieval for auditory words and visual pictures. J Neurosci 16, 6219-6235.

Congedo, M., 2002. EureKa! (Version 3.0) [Computer Software]. Knoxville, TN: NovaTech EEG Inc. Freeware available at www.NovaTechEEG.

Congedo, M., Finos, L., Turkheimer, F., 2004. A multiple hypothesis test procedure based on the sum of test-statistics. 10th Annual Meeting of the Organization for Human Brain Mapping, June 13-17, Budapest, Hungary. (Abstract) on CD.

Craig, A.D., 2002. How do you feel? Interoception: the sense of the physiological condition of the body. Nat Rev Neurosci 3, 655-666.

Craig, A.D., 2003. Interoception: the sense of the physiological condition of the body. Curr Opin Neurobiol 13, 500-505.

Critchley, H.D., 2005. Neural mechanisms of autonomic, affective, and cognitive integration. J Comp Neurol 493, 154-166.

Critchley, H.D., Corfield, D.R., Chandler, M.P., Mathias, C.J., Dolan, R.J., 2000. Cerebral correlates of autonomic cardiovascular arousal: a functional neuroimaging investigation in humans. J Physiol 523 Pt 1, 259-270. 
Critchley, H.D., Wiens, S., Rotshtein, P., Ohman, A., Dolan, R.J., 2004. Neural systems supporting interoceptive awareness. Nat Neurosci 7, 189-195.

De Ridder, D., De Mulder, G., Menovsky, T., Sunaert, S., Kovacs, S., 2007a. Electrical stimulation of auditory and somatosensory cortices for treatment of tinnitus and pain. Prog Brain Res 166, 377-388.

De Ridder, D., De Mulder, G., Verstraeten, E., Van der Kelen, K., Sunaert, S., Smits, M., Kovacs, S., Verlooy, J., Van de Heyning, P., Moller, A.R., 2006a. Primary and secondary auditory cortex stimulation for intractable tinnitus. ORL J Otorhinolaryngol Relat Spec 68, 48-54; discussion 54-45.

De Ridder, D., Fransen, H., Francois, O., Sunaert, S., Kovacs, S., Van De Heyning, P., $2006 b$. Amygdalohippocampal involvement in tinnitus and auditory memory. Acta Otolaryngol Suppl, 50-53.

De Ridder, D., van der Loo, E., Van der Kelen, K., Menovsky, T., van de Heyning, P., Moller, A., 2007b. Do tonic and burst TMS modulate the lemniscal and extralemniscal system differentially? Int J Med Sci 4, 242-246.

De Ridder, D., van der Loo, E., Van der Kelen, K., Menovsky, T., van de Heyning, P., Moller, A., 2007c. Theta, alpha and beta burst transcranial magnetic stimulation: brain modulation in tinnitus. Int J Med Sci 4, 237-241.

Diederen, K.M., Neggers, S.F., Daalman, K., Blom, J.D., Goekoop, R., Kahn, R.S., Sommer, I.E., Deactivation of the Parahippocampal Gyrus Preceding Auditory Hallucinations in Schizophrenia. Am J Psychiatry.

Eggermont, J.J., Roberts, L.E., 2004. The neuroscience of tinnitus. Trends Neurosci 27, 676-682.

Erlandsson, S.I., Holgers, K.M., 2001. The impact of perceived tinnitus severity on healthrelated quality of life with aspects of gender. Noise Health 3, 39-51. 
Flor, H., Elbert, T., Knecht, S., Wienbruch, C., Pantev, C., Birbaumer, N., Larbig, W., Taub, E., 1995. Phantom-limb pain as a perceptual correlate of cortical reorganization following arm amputation. Nature 375, 482-484.

Folmer, R.L., Griest, S.E., Martin, W.H., 2001. Chronic tinnitus as phantom auditory pain. Otolaryngol Head Neck Surg 124, 394-400.

Frysztak, R.J., Neafsey, E.J., 1994. The effect of medial frontal cortex lesions on cardiovascular conditioned emotional responses in the rat. Brain Res 643, 181-193.

Gardner, A., Pagani, M., Jacobsson, H., Lindberg, G., Larsson, S.A., Wagner, A., Hallstrom, T., 2002. Differences in resting state regional cerebral blood flow assessed with 99mTc-HMPAO SPECT and brain atlas matching between depressed patients with and without tinnitus. Nucl Med Commun 23, 429-439.

Giraud, A.L., Chery-Croze, S., Fischer, G., Fischer, C., Vighetto, A., Gregoire, M.C., Lavenne, F., Collet, L., 1999. A selective imaging of tinnitus. Neuroreport 10, 1-5.

Goebel, G., Hiller, W., 1994. [The tinnitus questionnaire. A standard instrument for grading the degree of tinnitus. Results of a multicenter study with the tinnitus questionnaire]. HNO 42, $166-172$.

Gray, J.R., Braver, T.S., Raichle, M.E., 2002. Integration of emotion and cognition in the lateral prefrontal cortex. Proc Natl Acad Sci U S A 99, 4115-4120.

Gray, J.R., Burgess, G.C., Schaefer, A., Yarkoni, T., Larsen, R.J., Braver, T.S., 2005. Affective personality differences in neural processing efficiency confirmed using fMRI. Cogn Affect Behav Neurosci 5, 182-190.

Hamalainen, H., Kujala, T., Kekoni, J., Hurskainen, H., Pirila, J., Wikstrom, H., Huotilainen, M., 2007. Effects of unilateral hippocampus-amygdala-partial temporal lobe resection on auditory EEG/MEG responses: a case study. Scand J Psychol 48, 367-373. 
Heller, A.J., 2003. Classification and epidemiology of tinnitus. Otolaryngol Clin North Am 36, 239-248.

Jastreboff, P.J., 1990. Phantom auditory perception (tinnitus): mechanisms of generation and perception. Neurosci Res 8, 221-254.

Jokic-Begic, N., Begic, D., 2003. Quantitative electroencephalogram (qEEG) in combat veterans with post-traumatic stress disorder (PTSD). Nord J Psychiatry 57, 351-355.

Kadner, A., Viirre, E., Wester, D.C., Walsh, S.F., Hestenes, J., Vankov, A., Pineda, J.A., 2002. Lateral inhibition in the auditory cortex: an EEG index of tinnitus? Neuroreport 13, 443-446.

Kahn, I., Andrews-Hanna, J.R., Vincent, J.L., Snyder, A.Z., Buckner, R.L., 2008. Distinct cortical anatomy linked to subregions of the medial temporal lobe revealed by intrinsic functional connectivity. J Neurophysiol 100, 129-139.

Kaltenbach, J.A., Afman, C.E., 2000. Hyperactivity in the dorsal cochlear nucleus after intense sound exposure and its resemblance to tone-evoked activity: a physiological model for tinnitus. Hear Res 140, 165-172.

Karniski, W., Blair, R.C., Snider, A.D., 1994. An exact statistical method for comparing topographic maps, with any number of subjects and electrodes. Brain Topogr 6, 203-210.

Kennerley, S.W., Walton, M.E., Behrens, T.E., Buckley, M.J., Rushworth, M.F., 2006. Optimal decision making and the anterior cingulate cortex. Nat Neurosci 9, 940-947.

Kleinjung, T., Eichhammer, P., Landgrebe, M., Sand, P., Hajak, G., Steffens, T., Strutz, J., Langguth, B., 2008. Combined temporal and prefrontal transcranial magnetic stimulation for tinnitus treatment: a pilot study. Otolaryngol Head Neck Surg 138, 497-501.

Klimesch, W., 1996. Memory processes, brain oscillations and EEG synchronization. Int J Psychophysiol 24, 61-100. 
Klimesch, W., Doppelmayr, M., Russegger, H., Pachinger, T., Schwaiger, J., 1998. Induced alpha band power changes in the human EEG and attention. Neurosci Lett 244, 73-76.

Klimesch, W., Doppelmayr, M., Schwaiger, J., Auinger, P., Winkler, T., 1999. 'Paradoxical' alpha synchronization in a memory task. Brain Res Cogn Brain Res 7, 493-501.

Knight, R.T., Scabini, D., Woods, D.L., 1989. Prefrontal cortex gating of auditory transmission in humans. Brain Res 504, 338-342.

Kovacs, S., Peeters, R., Smits, M., De Ridder, D., Van Hecke, P., Sunaert, S., 2006. Activation of cortical and subcortical auditory structures at $3 \mathrm{~T}$ by means of a functional magnetic resonance imaging paradigm suitable for clinical use. Invest Radiol 41, 87-96.

Landgrebe, M., Langguth, B., Rosengarth, K., Braun, S., Koch, A., Kleinjung, T., May, A., de Ridder, D., Hajak, G., 2009. Structural brain changes in tinnitus: grey matter decrease in auditory and non-auditory brain areas. Neuroimage 46, 213-218.

Lewis, J.W., Beauchamp, M.S., DeYoe, E.A., 2000. A comparison of visual and auditory motion processing in human cerebral cortex. Cereb Cortex 10, 873-888.

Llinas, R.R., Ribary, U., Jeanmonod, D., Kronberg, E., Mitra, P.P., 1999. Thalamocortical dysrhythmia: A neurological and neuropsychiatric syndrome characterized by magnetoencephalography. Proc Natl Acad Sci U S A 96, 15222-15227.

Lockwood, A.H., Salvi, R.J., Burkard, R.F., Galantowicz, P.J., Coad, M.L., Wack, D.S., 1999. Neuroanatomy of tinnitus. Scand Audiol Suppl 51, 47-52.

Margulies, D.S., Kelly, A.M., Uddin, L.Q., Biswal, B.B., Castellanos, F.X., Milham, M.P., 2007. Mapping the functional connectivity of anterior cingulate cortex. Neuroimage 37, 579-588.

Masten, C.L., Eisenberger, N.I., Borofsky, L.A., Pfeifer, J.H., McNealy, K., Mazziotta, J.C., Dapretto, M., 2009. Neural correlates of social exclusion during adolescence: understanding the distress of peer rejection. Soc Cogn Affect Neurosci 4, 143-157. 
Meeus, O., Blaivie, C., Van de Heyning, P., 2007. Validation of the Dutch and the French version of the Tinnitus Questionnaire. B-ENT 3 Suppl 7, 11-17.

Melcher, J.R., Sigalovsky, I.S., Guinan, J.J., Jr., Levine, R.A., 2000. Lateralized tinnitus studied with functional magnetic resonance imaging: abnormal inferior colliculus activation. $\mathbf{J}$ Neurophysiol 83, 1058-1072.

Mirz, F., Gjedde, A., Ishizu, K., Pedersen, C.B., 2000a. Cortical networks subserving the perception of tinnitus--a PET study. Acta Otolaryngol Suppl 543, 241-243.

Mirz, F., Gjedde, A., Sodkilde-Jrgensen, H., Pedersen, C.B., 2000b. Functional brain imaging of tinnitus-like perception induced by aversive auditory stimuli. Neuroreport 11, 633-637.

Mirz, F., Pedersen, B., Ishizu, K., Johannsen, P., Ovesen, T., Stodkilde-Jorgensen, H., Gjedde, A., 1999. Positron emission tomography of cortical centers of tinnitus. Hear Res 134, 133 144.

Mitchell, T.V., Morey, R.A., Inan, S., Belger, A., 2005. Functional magnetic resonance imaging measure of automatic and controlled auditory processing. Neuroreport 16, 457-461.

Mobascher, A., Brinkmeyer, J., Warbrick, T., Musso, F., Wittsack, H.J., Saleh, A., Schnitzler, A., Winterer, G., 2009. Laser-evoked potential P2 single-trial amplitudes covary with the fMRI BOLD response in the medial pain system and interconnected subcortical structures. Neuroimage.

Moisset, X., Bouhassira, D., 2007. Brain imaging of neuropathic pain. Neuroimage 37 Suppl 1, S80-88.

Moller, A.R., 1997. Similarities between chronic pain and tinnitus. Am J Otol 18, 577-585.

Moller, A.R., 2000. Similarities between severe tinnitus and chronic pain. J Am Acad Audiol 11, 115-124. 
Muhlau, M., Rauschecker, J.P., Oestreicher, E., Gaser, C., Rottinger, M., Wohlschlager, A.M., Simon, F., Etgen, T., Conrad, B., Sander, D., 2006. Structural brain changes in tinnitus. Cereb Cortex 16, 1283-1288.

Muhlnickel, W., Elbert, T., Taub, E., Flor, H., 1998. Reorganization of auditory cortex in tinnitus. Proc Natl Acad Sci U S A 95, 10340-10343.

Mulert, C., Jager, L., Schmitt, R., Bussfeld, P., Pogarell, O., Moller, H.J., Juckel, G., Hegerl, U., 2004. Integration of fMRI and simultaneous EEG: towards a comprehensive understanding of localization and time-course of brain activity in target detection. Neuroimage 22, 83-94.

Newman, C.W., Wharton, J.A., Jacobson, G.P., 1997. Self-focused and somatic attention in patients with tinnitus. J Am Acad Audiol 8, 143-149.

Norena, A., Cransac, H., Chery-Croze, S., 1999. Towards an objectification by classification of tinnitus. Clin Neurophysiol 110, 666-675.

Ongur, D., Price, J.L., 2000. The organization of networks within the orbital and medial prefrontal cortex of rats, monkeys and humans. Cereb Cortex 10, 206-219.

Oppenheimer, S., 1993. The anatomy and physiology of cortical mechanisms of cardiac control. Stroke 24, I3-5.

Oppenheimer, S.M., Gelb, A., Girvin, J.P., Hachinski, V.C., 1992. Cardiovascular effects of human insular cortex stimulation. Neurology 42, 1727-1732.

Pascual-Marqui, R.D., Esslen, M., Kochi, K., Lehmann, D., 2002. Functional imaging with lowresolution brain electromagnetic tomography (LORETA): a review. Methods Find Exp Clin Pharmacol 24 Suppl C, 91-95.

Pascual-Marqui, R.D., Lehmann, D., Koenig, T., Kochi, K., Merlo, M.C., Hell, D., Koukkou, M., 1999. Low resolution brain electromagnetic tomography (LORETA) functional imaging in acute, neuroleptic-naive, first-episode, productive schizophrenia. Psychiatry Res 90, 169-179. 
Pascual-Marqui, R.D., Michel, C.M., Lehmann, D., 1994. Low resolution electromagnetic tomography: a new method for localizing electrical activity in the brain. Int J Psychophysiol $18,49-65$.

Peyron, R., Laurent, B., Garcia-Larrea, L., 2000. Functional imaging of brain responses to pain. A review and meta-analysis (2000). Neurophysiol Clin 30, 263-288.

Phan, K.L., Wager, T., Taylor, S.F., Liberzon, I., 2002. Functional neuroanatomy of emotion: a meta-analysis of emotion activation studies in PET and fMRI. Neuroimage 16, 331-348.

Plewnia, C., Reimold, M., Najib, A., Brehm, B., Reischl, G., Plontke, S.K., Gerloff, C., 2007a. Dose-dependent attenuation of auditory phantom perception (tinnitus) by PET-guided repetitive transcranial magnetic stimulation. Hum Brain Mapp 28, 238-246.

Plewnia, C., Reimold, M., Najib, A., Reischl, G., Plontke, S.K., Gerloff, C., 2007b. Moderate therapeutic efficacy of positron emission tomography-navigated repetitive transcranial magnetic stimulation for chronic tinnitus: a randomised, controlled pilot study. J Neurol Neurosurg Psychiatry 78, 152-156.

Price, D.D., 2000. Psychological and neural mechanisms of the affective dimension of pain. Science 288, 1769-1772.

Salvi, R.J., Wang, J., Ding, D., 2000. Auditory plasticity and hyperactivity following cochlear damage. Hear Res 147, 261-274.

Schlee, W., Weisz, N., Bertrand, O., Hartmann, T., Elbert, T., 2008. Using auditory steady state responses to outline the functional connectivity in the tinnitus brain. PLoS ONE 3, e3720.

Scott, B., Lindberg, P., 2000. Psychological profile and somatic complaints between helpseeking and non-help-seeking tinnitus subjects. Psychosomatics 41, 347-352.

Shulman, A., 1995. A Final Common Pathway for Tinnitus - The Medial Temporal Lobe System. Int Tinnitus J 1, 115-126. 
Smits, M., Kovacs, S., de Ridder, D., Peeters, R.R., van Hecke, P., Sunaert, S., 2007. Lateralization of functional magnetic resonance imaging (fMRI) activation in the auditory pathway of patients with lateralized tinnitus. Neuroradiology 49, 669-679.

Stein, J.L., Wiedholz, L.M., Bassett, D.S., Weinberger, D.R., Zink, C.F., Mattay, V.S., MeyerLindenberg, A., 2007. A validated network of effective amygdala connectivity. Neuroimage $36,736-745$.

Talairach, J., Tournoux, P., 1988. Co-Planar Stereotaxic Atlas of the Human Brain. Thieme, New York.

Tonndorf, J., 1987. The analogy between tinnitus and pain: a suggestion for a physiological basis of chronic tinnitus. Hear Res 28, 271-275.

van der Loo, E., Gais, S., Congedo, M., Vanneste, S., Plazier, M., Menovsky, T., Van de Heyning, P., De Ridder, D., 2009. Tinnitus intensity dependent gamma oscillations of the contralateral auditory cortex. PLoS ONE 4, e7396.

Vermetten, E., Schmahl, C., Southwick, S.M., Bremner, J.D., 2007. Positron tomographic emission study of olfactory induced emotional recall in veterans with and without combatrelated posttraumatic stress disorder. Psychopharmacol Bull 40, 8-30.

Vincent, J.L., Kahn, I., Snyder, A.Z., Raichle, M.E., Buckner, R.L., 2008. Evidence for a frontoparietal control system revealed by intrinsic functional connectivity. J Neurophysiol $100,3328-3342$.

Viskontas, I.V., Knowlton, B.J., Steinmetz, P.N., Fried, I., 2006. Differences in mnemonic processing by neurons in the human hippocampus and parahippocampal regions. J Cogn Neurosci 18, 1654-1662.

Vogt, B.A., Finch, D.M., Olson, C.R., 1992. Functional heterogeneity in cingulate cortex: the anterior executive and posterior evaluative regions. Cereb Cortex 2, 435-443. 
Voisin, J., Bidet-Caulet, A., Bertrand, O., Fonlupt, P., 2006. Listening in silence activates auditory areas: a functional magnetic resonance imaging study. J Neurosci 26, 273-278. von Leupoldt, A., Sommer, T., Kegat, S., Baumann, H.J., Klose, H., Dahme, B., Buchel, C., 2009. Dyspnea and pain share emotion-related brain network. Neuroimage 48, 200-206.

Wang, J., Rao, H., Wetmore, G.S., Furlan, P.M., Korczykowski, M., Dinges, D.F., Detre, J.A., 2005. Perfusion functional MRI reveals cerebral blood flow pattern under psychological stress. Proc Natl Acad Sci U S A 102, 17804-17809.

Weisz, N., Dohrmann, K., Elbert, T., 2007. The relevance of spontaneous activity for the coding of the tinnitus sensation. Prog Brain Res 166, 61-70.

Weisz, N., Moratti, S., Meinzer, M., Dohrmann, K., Elbert, T., 2005. Tinnitus perception and distress is related to abnormal spontaneous brain activity as measured by magnetoencephalography. PLoS Med 2, e153.

Weisz, N., Voss, S., Berg, P., Elbert, T., 2004. Abnormal auditory mismatch response in tinnitus sufferers with high-frequency hearing loss is associated with subjective distress level. BMC Neurosci 5, 8 .

Wilson, C.L., Babb, T.L., Halgren, E., Wang, M.L., Crandall, P.H., 1984. Habituation of human limbic neuronal response to sensory stimulation. Exp Neurol 84, 74-97.

Yoo, S.S., Lee, C.U., Choi, B.G., 2001. Human brain mapping of auditory imagery: event-related functional MRI study. Neuroreport 12, 3045-3049.

Zald, D.H., Pardo, J.V., 2002. The neural correlates of aversive auditory stimulation. Neuroimage 16, 746-753. 
Table 1. Population statistics

\begin{tabular}{|c|c|c|c|c|c|}
\hline & \multicolumn{4}{|c|}{ Tinnitus Grade } \\
\hline & & 1 & 2 & 3 & 4 \\
\hline \multirow[t]{2}{*}{$\operatorname{sex}$} & Male & 3 & 3 & 3 & 2 \\
\hline & Female & 3 & 4 & 4 & 5 \\
\hline \multirow[t]{2}{*}{ age } & $M$ & 56.40 & 51.50 & 52.00 & 58.80 \\
\hline & $S D$ & 11.97 & 11.15 & 14.89 & 8.20 \\
\hline \multirow[t]{2}{*}{ duration } & $M$ & 4.10 & 5.58 & 6.57 & 4.60 \\
\hline & $S D$ & 3.85 & 5.00 & 5.50 & 3.36 \\
\hline \multirow[t]{2}{*}{ type } & Pure Tone & 2 & 2 & 2 & 2 \\
\hline & Narrow Band Noise & 4 & 5 & 5 & 5 \\
\hline \multirow[t]{2}{*}{ laterality } & Unilateral & 2 & 4 & 4 & 5 \\
\hline & Bilateral & 4 & 3 & 3 & 2 \\
\hline
\end{tabular}


Table 2. $t$-scores for each variable included in the regression model for respectively Alpha1 and Alpha 2 frequency band.

\begin{tabular}{|c|c|c|c|}
\hline $\mathbf{B A}$ & Region & Side & $t$-score \\
\hline \multicolumn{4}{|c|}{$\begin{array}{l}\text { Alphal } \\
\text { Model: } \\
\text { TQ = 26.90-17.98 BA9-46 + } 19.83 \text { BA25 }\end{array}$} \\
\hline $\begin{array}{l}\text { BA9-46 } \\
\text { BA25 }\end{array}$ & $\begin{array}{l}\text { DLPFC } \\
\text { scACC }\end{array}$ & $\begin{array}{c}\mathrm{R} \\
\mathrm{L}+\mathrm{R} \\
\end{array}$ & $\begin{array}{c}3.01 \\
-2.22 \\
\end{array}$ \\
\hline \multicolumn{4}{|c|}{$\begin{array}{l}\text { Alpha } 2 \\
\text { Model: } \\
\text { TQ }=33.95-19.92 \mathrm{BA} 9-46+116.71 \mathrm{BA} 23 \mathrm{~L}-120.56 \mathrm{BA} 23 \mathrm{R}+25.86 \mathrm{BA} 25-19.57 \mathrm{BA} 36-37 \mathrm{~L}+22.00 \mathrm{BA} 36-37 \mathrm{R}\end{array}$} \\
\hline $\begin{array}{l}\text { BA9-46 } \\
\text { BA23 } \\
\text { BA23 } \\
\text { BA25 } \\
\text { BA36-37 } \\
\text { BA36-37 }\end{array}$ & $\begin{array}{l}\text { DLPFC } \\
\text { PCC } \\
\text { PCC } \\
\text { scACC } \\
\text { Parahippocampal area } \\
\text { Parahippocampal area }\end{array}$ & $\begin{array}{c}\mathrm{R} \\
\mathrm{L} \\
\mathrm{R} \\
\mathrm{L}+\mathrm{R} \\
\mathrm{L} \\
\mathrm{R}\end{array}$ & $\begin{array}{l}2.18 \\
1.81 \\
1.90 \\
2.03 \\
-2.00 \\
2.06\end{array}$ \\
\hline
\end{tabular}

Abbreviations: L: left; R: right 
Table 3. Summary of Results

\begin{tabular}{|c|c|c|}
\hline \multicolumn{3}{|c|}{ High vs. Low distress } \\
\hline Increased & alpha1 $(8-10 \mathrm{~Hz})$ & $\begin{array}{l}\text { amygdala } \\
\text { parahippocampal gyrus (BA36) } \\
\text { nucleus accumbens-VTA area } \\
\text { subcallosal anterior cingulate (BA25) }\end{array}$ \\
\hline \multirow{3}{*}{ Decreased } & alpha2 $(10.5-12.5 \mathrm{~Hz})$ & $\begin{array}{l}\text { amygdala } \\
\text { middle temporal gyrus (BA21) } \\
\text { parahippocampal gyrus (BA36 and 37) }\end{array}$ \\
\hline & alpha1 $(8-10 \mathrm{~Hz})$ & - \\
\hline & alpha2 $(10.5-12.5 \mathrm{~Hz})$ & $\begin{array}{l}\text { posterior cingulate (BA23) } \\
\text { precuneus (BA7) }\end{array}$ \\
\hline \multicolumn{3}{|c|}{ Non-coping vs. Coping } \\
\hline \multirow[t]{2}{*}{ Increased } & alpha1 $(8-10 \mathrm{~Hz})$ & $\begin{array}{l}\text { amygdala } \\
\text { anterior cingulate (BA25) } \\
\text { insula (BA 13) } \\
\text { parahippocampal gyrus (BA37) } \\
\text { subcallosal gyrus (BA25) }\end{array}$ \\
\hline & alpha2 $(10.5-12.5 \mathrm{~Hz})$ & $\begin{array}{l}\text { amygdala } \\
\text { insula (BA13) } \\
\text { parahippocampal gyrus (BA36) } \\
\text { subcallosal gyrus (BA25) }\end{array}$ \\
\hline \multirow[t]{2}{*}{ Decreased } & alpha1 $(8-10 \mathrm{~Hz})$ & precuneus (BA7) \\
\hline & alpha2 $(10.5-12.5 \mathrm{~Hz})$ & $\begin{array}{l}\text { precuneus (BA7) } \\
\text { posterior cingulate (BA23) }\end{array}$ \\
\hline
\end{tabular}

Coping: High vs. Low distress

Increased $\quad$ alpha1 $(8-10 \mathrm{~Hz})$

alpha2 (10.5-12.5 Hz) precuneus (BA7)

Decreased alpha1 $(8-10 \mathrm{~Hz}) \quad$ dorsal lateral prefrontal cortex (BA9 and BA46)

precentral gyrus (BA6)

alpha2 (10.5-12.5 Hz) dorsal lateral prefrontal cortex (BA9 and BA46)

ventrolateral prefrontal cortex (BA8) 




Fig. 1. Significant results for current density amplitude analysis in the alpha1band. LORETA current source density in the alpha1 $(8-10 \mathrm{~Hz})$ band was higher in high distress tinnitus patients than among low distress tinnitus patient in the subcallosal anterior cingulate gyrus (BA25), parahippocampal gyrus (BA36) and amygdala. Coordinates and $t$-values for the voxel are printed above the picture of the sagittal section. All $t$-statistic that are positive, are displayed in red (high distress tinnitus patients than among low distress tinnitus patient). Displayed are the horizontal (left) sagittal (middle), and coronal (right) sections through the voxel with maximal $t$-statistic. This image shows significant results only. 


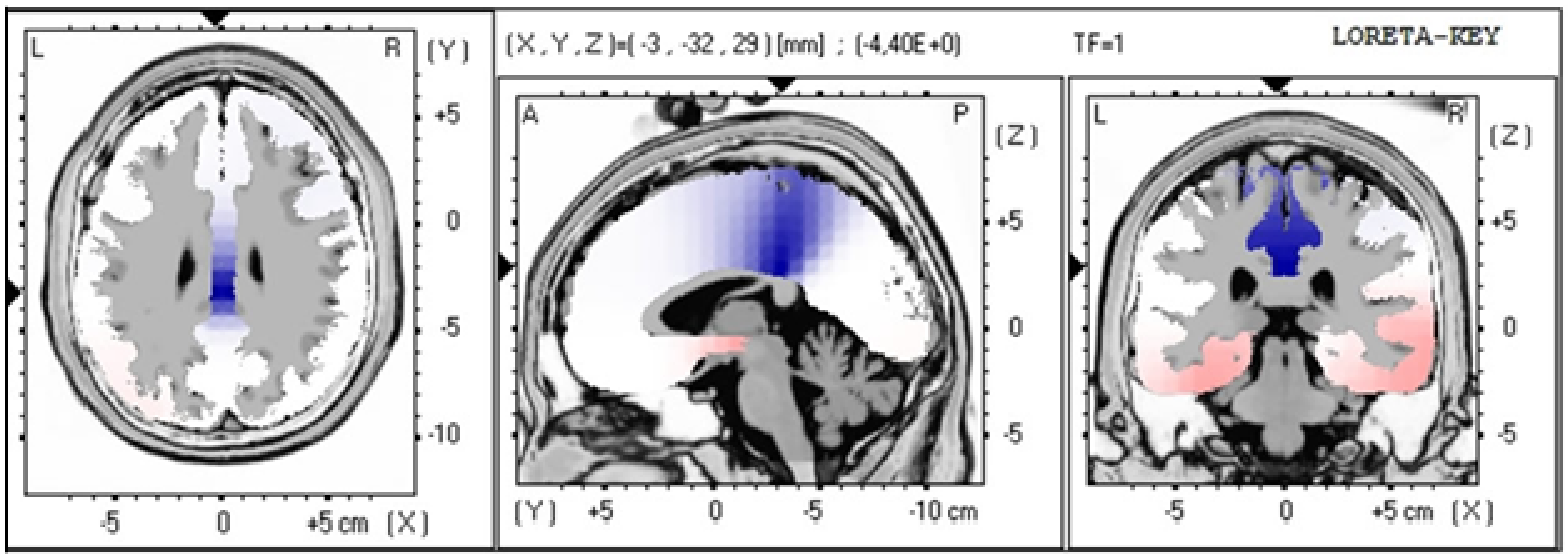

Fig. 2. Significant results for current density amplitude analysis in the alpha2 band. LORETA current source density in the alpha2 $(10.5-12.5 \mathrm{~Hz})$ band was high distress tinnitus patients than among low distress tinnitus patient in the parahippocampal gyrus (BA36 and 37), amygdala and in extension the middle temporal gyrus (BA21) and the opposite for the posterior cingulate (BA23), and precuneus (BA7). Coordinates and $t$-values for the voxel are printed above the picture of the sagittal section. $t$-statistic that are positive, are displayed in red (the mean of high distress tinnitus patients was greater than the mean low distress tinnitus patient) and negative, are displayed in blue (the mean low distress tinnitus patients greater than mean in high distress tinnitus patient). Displayed are the horizontal (left) sagittal (middle), and coronal (right) sections through the voxel with maximal $t$-statistic. This image shows significant results only. 


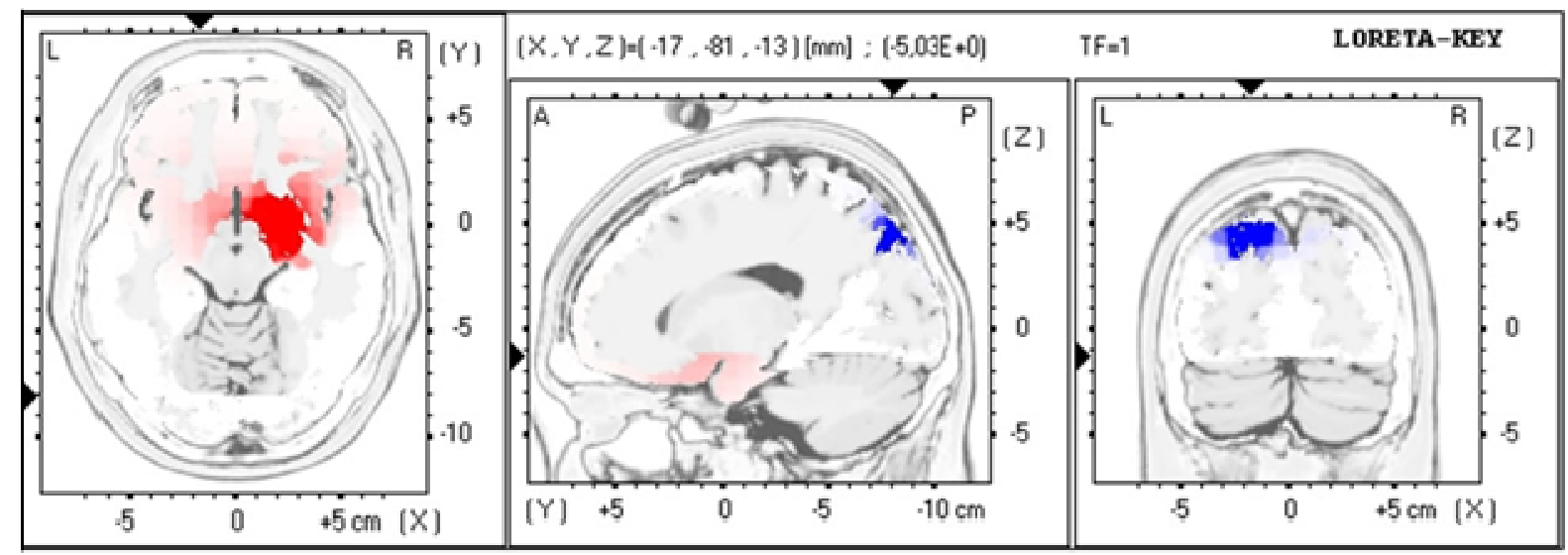

Fig. 3. Significant results for current density amplitude analysis in the alpha1 band. LORETA current source density in the alphal $(8-10 \mathrm{~Hz})$ band was higher in higher for non-coping tinnitus patients than among tinnitus patient who can cope with their tinnitus in the insula (BA 13), anterior cingulate (BA25), subcallosal gyrus (BA25), parahippocampal gyrus (BA37) and amygdala and the opposite for precuneus (BA7). Coordinates and $t$-values for the voxel are printed above the picture of the sagittal section. $t$-statistic that are positive, are displayed in red (the mean for non-coping tinnitus patients is greater than the mean of tinnitus patient who can cope with their tinnitus) and negative, are displayed in blue (the mean for coping tinnitus patients is greater than the mean of tinnitus patient who cannot cope with their tinnitus). Displayed are the horizontal (left) sagittal (middle), and coronal (right) sections through the voxel with maximal $t$-statistic. This image shows significant results only. 


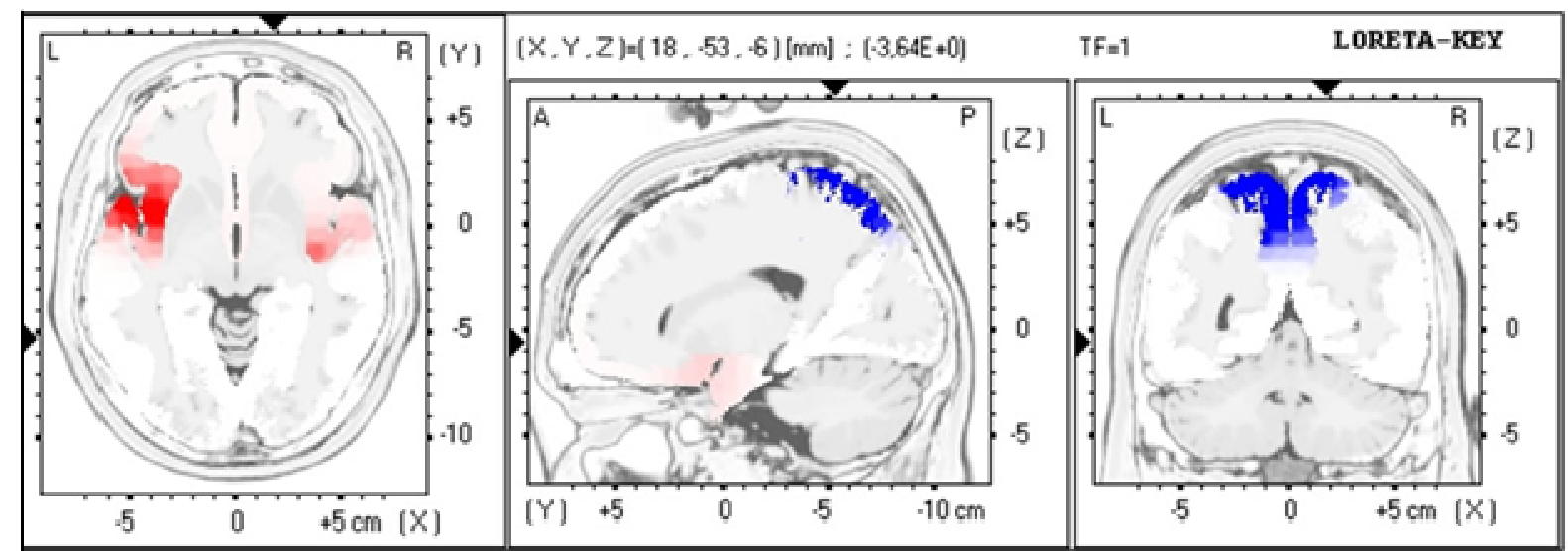

Fig. 4. Significant results for current density amplitude analysis in the alpha2 band. LORETA current source density in the alpha1 $(10.5-12.5 \mathrm{~Hz})$ band was higher in higher for non-coping tinnitus patients than among tinnitus patient who can cope with their tinnitus in the insula (BA13) subcallosal gyrus (BA25), parahippocampal gyrus (BA36) and amygdala and the opposite for precuneus (BA7). Coordinates and $t$-values for the voxel are printed above the picture of the sagittal section. $t$-statistic that are positive, are displayed in red (the mean for coping tinnitus patients with high distress is greater than the mean of tinnitus patient who can cope with low distress) and negative, are displayed in blue (the mean for coping tinnitus patients with low distress is greater than the mean of tinnitus patient who can cope with high distress). Displayed are the horizontal (left) sagittal (middle), and coronal (right) sections through the voxel with maximal $t$-statistic. This image shows significant results only. 


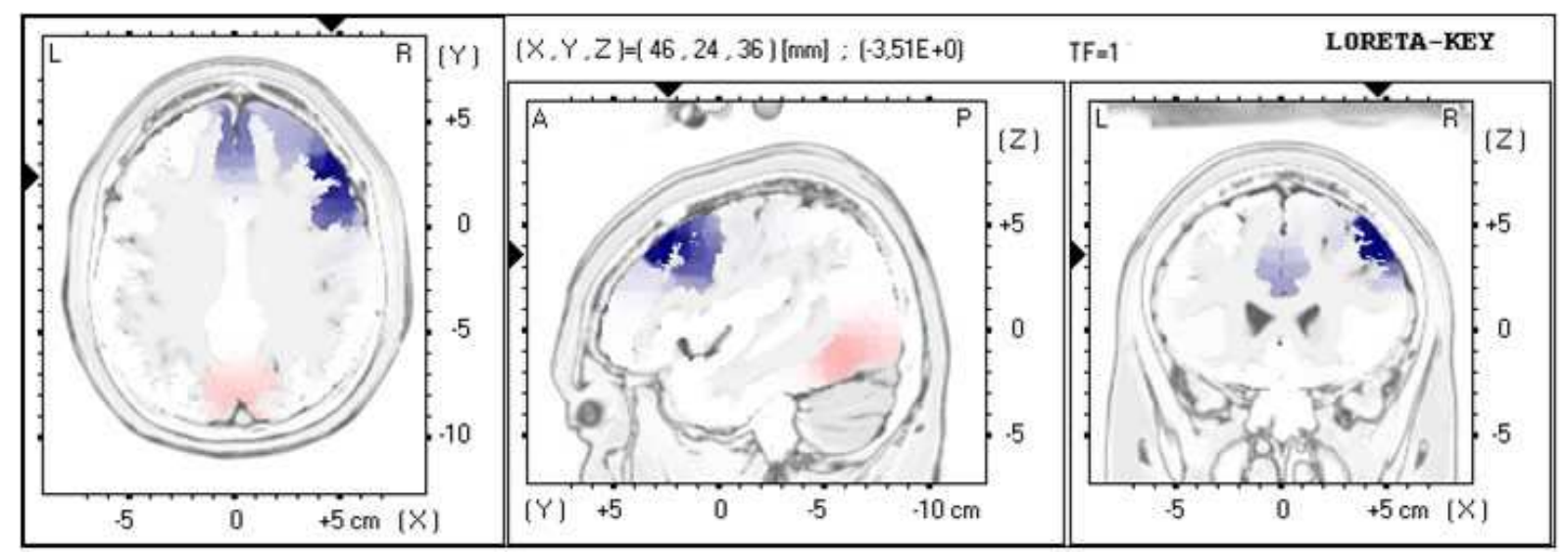

Fig. 5. Significant results for current density amplitude analysis in the alpha1 band. LORETA current source density in the alpha1 $(8-10 \mathrm{~Hz})$ band was higher in low distress coping tinnitus patients than among high distress coping tinnitus patients in the dorsal lateral prefrontal cortex (BA9 and BA46) and precentral gyrus (BA6). Coordinates and $t$-values for the voxel are printed above the picture of the sagittal section. $t$-statistic that are positive, are displayed in red (the mean of high distress coping tinnitus patients was greater than the low distress coping tinnitus patients) and negative, are displayed in blue (the mean of low distress coping tinnitus patients was greater than the high distress coping tinnitus patients). Displayed are the horizontal (left) sagittal (middle), and coronal (right) sections through the voxel with maximal $t$-statistic. This image shows significant results only. 


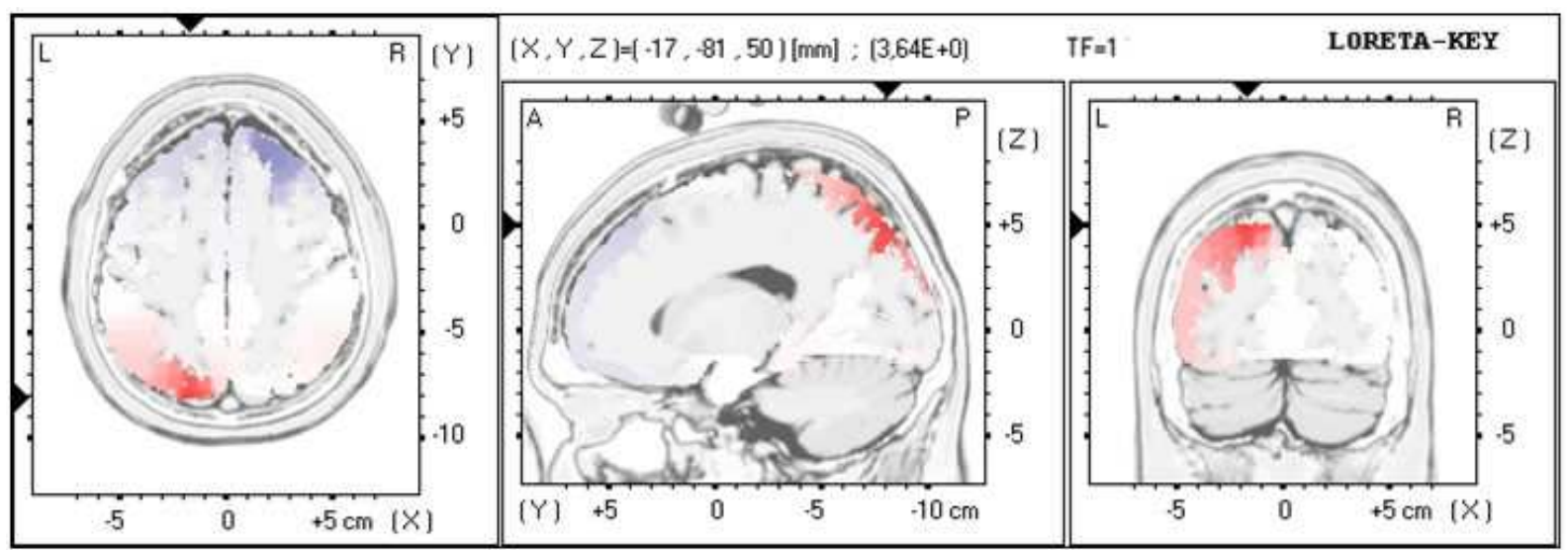

Fig. 6. Significant results for current density amplitude analysis in the alpha2 band. LORETA current source density in the alpha1 $(10.5-12.5 \mathrm{~Hz})$ band was higher in high distress coping tinnitus patients than among low distress coping tinnitus patients in the precuneus (BA7) the opposite for dorsal lateral prefrontal cortex (BA9 and BA46) and ventrolateral prefrontal cortex (BA8). Coordinates and $t$-values for the voxel are printed above the picture of the sagittal section. $t$-statistic that positive, are displayed in red (the mean of high distress coping tinnitus patients was greater than the low distress coping tinnitus patients) and negative, are displayed in blue (the mean of low distress coping tinnitus patients was greater than the high distress coping tinnitus patients). Displayed are the horizontal (left) sagittal (middle), and coronal (right) sections through the voxel with maximal $t$-statistic. This image shows significant results only. 


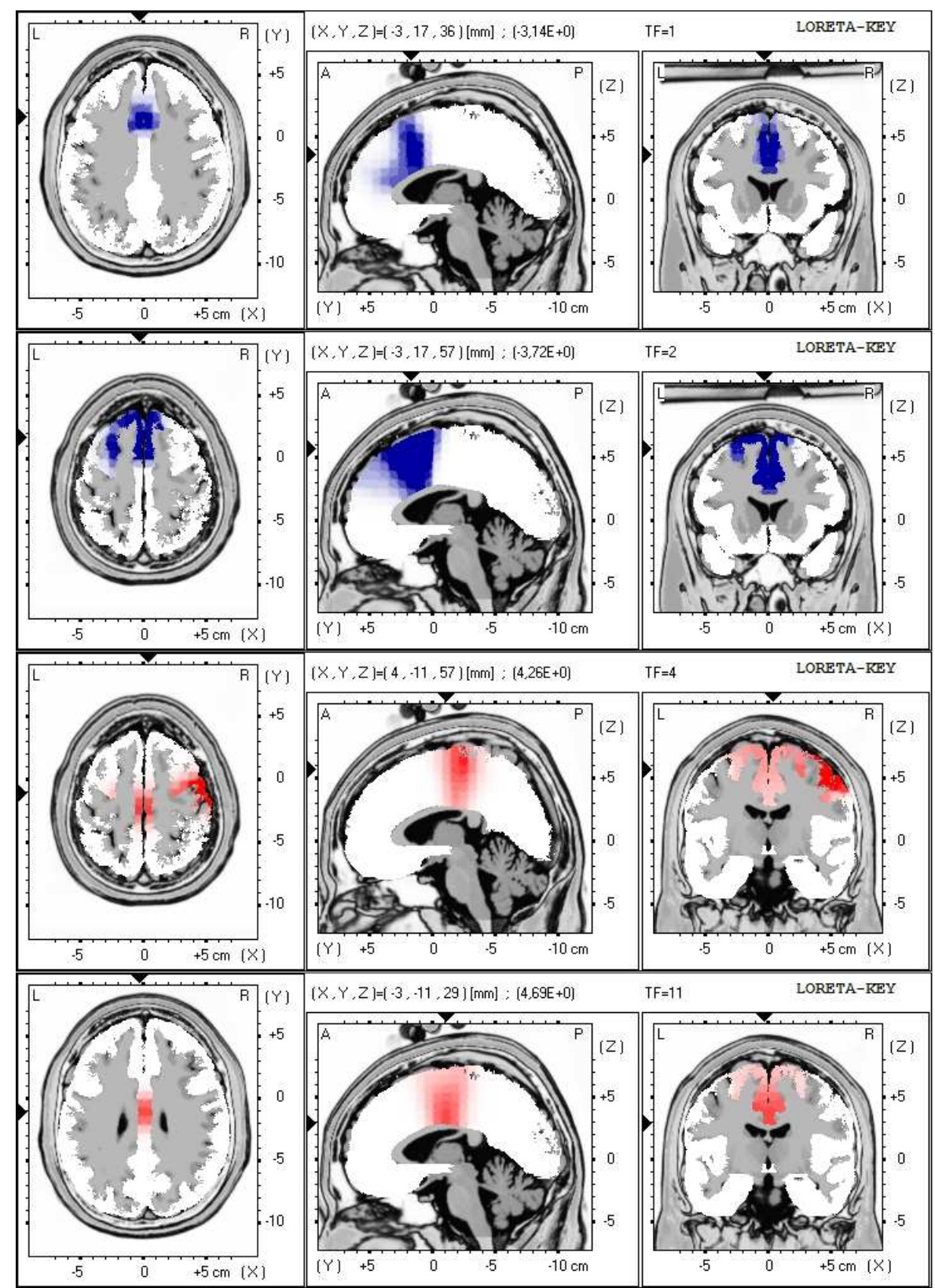

Fig. 7. Significant results for current density amplitude analysis in respectively delta, theta, alpha (alpha1 + alpha 2) and beta3. LORETA current source density in delta (2-3.5 Hz) en theta (4-7.5 Hz), was lower in distressed tinnitus patients than in a control group, while for alpha (8$12.5 \mathrm{~Hz})$ and beta3 $(21-24.5 \mathrm{~Hz})$ was higher distressed tinnitus patients than in a control group in cingulate cortex (BA24 BA32). Similar to beta3, also significant difference were found for beta4 $(25-28.5 \mathrm{~Hz})$ and beta5 $(29-32.5 \mathrm{~Hz})$. 
